\title{
Flowability, Tear Strength, and Hydrophilicity of Current Elastomers for Dental Impressions
}

\author{
Fabian Huettig ${ }^{1, *(\mathbb{D}}$, Andrea Klink ${ }^{1} \mathbb{D}$, Alexander Kohler ${ }^{2}$, Moritz Mutschler ${ }^{1}$ and Frank Rupp ${ }^{2} \mathbb{D}$ \\ 1 Department of Prosthodontics at the University Clinic for Dentistry, Oral Medicine, and Maxillofacial Surgery, \\ University Hospital Tübingen, Osianderstr. 2-8, 72076 Tübingen, Germany; \\ andrea.klink@med.uni-tuebingen.de (A.K.); moritz.mutschler@frs-nt.de (M.M.) \\ 2 Section Medical Materials Science and Technology, Department of Biomedical Engeneering, \\ University Hospital Tübingen, Osianderstr. 2-8, 72076 Tübingen, Germany; \\ kohleralexander@yahoo.de (A.K.); frank.rupp@med.uni-tuebingen.de (F.R.) \\ * Correspondence: fabian.huettig@med.uni-tuebingen.de; Tel.: +49-7071-29-83983
}

Citation: Huettig, F.; Klink, A. Kohler, A.; Mutschler, M.; Rupp, F. Flowability, Tear Strength, and Hydrophilicity of Current Elastomers for Dental Impressions. Materials 2021, 14, 2994. https:// doi.org/10.3390/ma14112994

Academic Editor: Gianrico Spagnuolo

Received: 17 March 2021

Accepted: 28 May 2021

Published: 1 June 2021

Publisher's Note: MDPI stays neutral with regard to jurisdictional claims in published maps and institutional affiliations.

Copyright: (c) 2021 by the authors. Licensee MDPI, Basel, Switzerland. This article is an open access article distributed under the terms and conditions of the Creative Commons Attribution (CC BY) license (https:// creativecommons.org/licenses/by/ $4.0 /)$.

\begin{abstract}
This study investigates 2 polyethers (PE), 2 polyvinylsiloxanethers (VXSE), and 10 polyvinylsiloxanes (PVS), seven of which had a corresponding light-body consistency and seven of which had a corresponding heavy-body consistency. Each light-body elastomer underwent a flowability test using the shark fin method 20,50, and $80 \mathrm{~s}$ after mixing. The tear strength test DIN 53504 was used after setting the time (T0). Next, $24 \mathrm{~h}$ later (T1), hydrophilicity testing was used with static contact angles in water drops during polymerization $(20,50$, and $80 \mathrm{~s}$, as well as after $10 \mathrm{~min}$ ). The heavy-body elastomers underwent shark fin testing with a corresponding light-body material at 50 and $80 \mathrm{~s}$ after mixing. The results of light-body testing were combined in a score to describe their performance. The highest differences were detected within flowability in shark fin heights between PE and a PVS (means of 15.89 and $6.85 \mathrm{~mm}$ ) within the maximum tear strengths at T0 between a PVS and PE (3.72 and $0.75 \mathrm{MPa}$ ), as well as within hydrophilicity during setting between VXSE and a PVS $\left(15.09^{\circ}\right.$ and $\left.75.5^{\circ}\right)$. The results indicate that VSXE and novel PVS materials can significantly compensate shortcomings in PE towards tear strength and hydrophilicity, but not flowability.
\end{abstract}

Keywords: dental prosthesis; dental materials; dentistry; silicone; dental cast; precision; denture

\section{Introduction}

Apart from progress in digitalization and optical acquisition of teeth and jaws, conventional impressions still plays a major role in daily dental practice worldwide. Therefore, improved elastomers are still apart of the dental industry's R\&D focus, as they facilitate precise working casts for restorations and all kinds of dental prostheses, including implants. This is evident through the launch of improved or even novel materials by major companies. Current elastomeric impression materials encompass two prevalent material classes: polyvinylsiloxanes and polyethers [1,2], each of which are supplemented with the "novel" hybrid class polyvinylsiloxanether [3].

Unfortunately, there is insufficient data regarding the current state of elastomers when taking dental impressions. Much of the literature is outdated and cites material characteristics from the late 1990s and early 2000s [4,5]. For elastomers, a large number of properties determine a dentist's basic decision to use a specific material, which allows its appropriateness in individual clinical cases and broad applications [6].

This addresses a bunch of variables:

- $\quad$ price, storability, and shelf life

- $\quad$ patient comfort (e.g., taste, demolding force)

- $\quad$ available viscosities and their flowability during impressions

- $\quad$ compatibility with astringents or disinfectants

- dimensional stability (over time of transport to the dental lab, reset after compression) 
- tolerance towards moisture during impression taking and when pouring the cast - tear strength to avoid ruptures when demolding from the jaw and/or the gypsum cast

Normally, elastomers shall convey details and dimension without deviations or loss of information from the oral cavity to a working cast. After an impression was taken, the dentist has to visually check the quality of the negative. Dimensional errors are undetectable, but failures or shortcomings appear in reproductions, such as blisters, ruptures, displacement, or incomplete merging (throw) of material (see Figure 1).

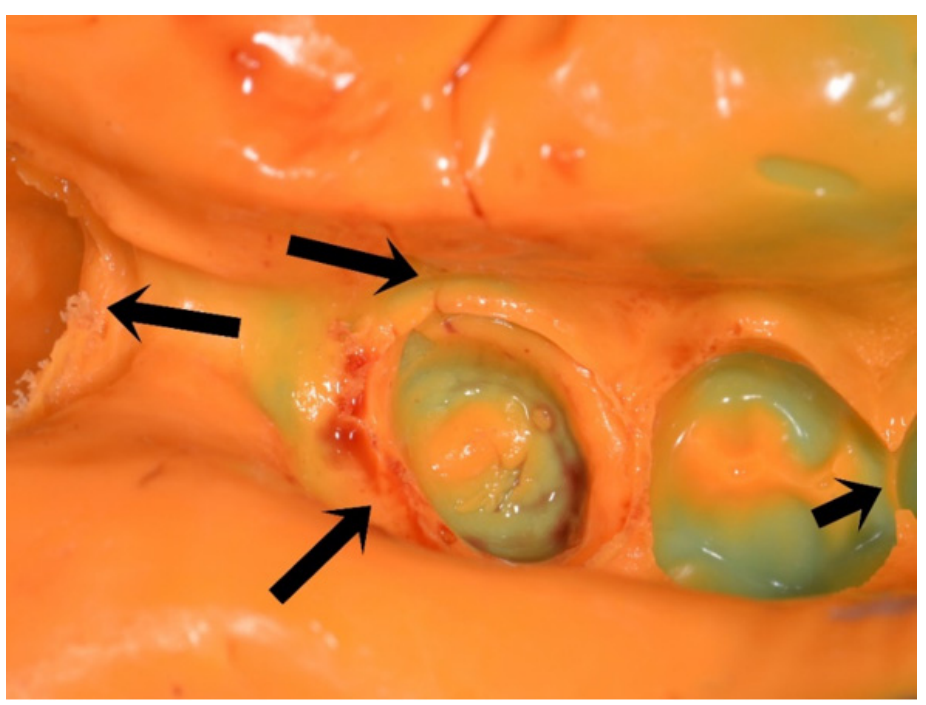

Figure 1. Premolar region of a double mixing impression for a fixed dental prosthesis made from a light-body (orange) and heavy-body (green) polyvinylsiloxane elastomer. The left and right arrow mark ruptures that suffered a loss of material. The top arrow shows a throw of material forming a cleft that intersects the finishing line of the preparation due to an incomplete merging of the material. The lower arrow points at surface changes due to moisture/ blood interaction.

In consequence, the most relevant properties for detailed reproduction are flowability, tear strength, and hydrophilicity. Thus, a material-specific study should evaluate single properties and investigate the most relevant properties from the 14 current elastomers available on the global market (Table 1):

(1) Flowability with regard to the competence to reach and copy complex geometries such as subgingival finishing lines or microtopographical surface features [7].

(2) Tear strength when demolding the impression from the jaw after setting time, as well as $24 \mathrm{~h}$ later when the impression demolds from the gypsum cast.

(3) Hydrophilicity with regard to the capacity to flow on dry and moist surfaces during impression taking (initial contact after mixing) [7,8], as well as when the impression is fully polymerized (about $8 \mathrm{~min}$ after setting) to be poured in the dental lab.

Based on this, we aimed to investigate flowability, hydrophilicity, and tear strength of selected marketed elastomeric impression materials, as well as to evaluate their overall performance with a metric score. Light-body materials were of major interest because they have first contact with the hard and soft tissues and are able to convey their surfaces and details after setting (see Figure 2). 


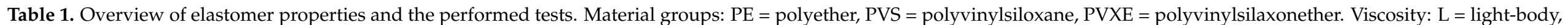

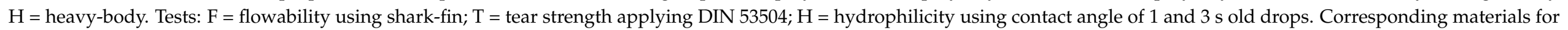
wash impression technique are grouped in one row (e.g., AqH-AqL).

\begin{tabular}{|c|c|c|c|c|c|c|c|c|c|}
\hline Material Group & Viscosity & $\begin{array}{l}\text { Abbreviation } \\
\text { Study Group }\end{array}$ & Materials Brand Name & Manufacturer & LOT\# & $\begin{array}{l}\text { Exp. Date Year- } \\
\text { Month }\end{array}$ & $\begin{array}{c}\text { Processing } \\
\text { Time (s) }\end{array}$ & $\begin{array}{l}\text { Setting } \\
\text { Time (s) }\end{array}$ & Tests \\
\hline PVS & $\mathrm{H}$ & $\mathrm{AqH}$ & Aquasil Ultra+ Heavy & \multirow{2}{*}{ Dentsply } & 180103 & January 2021 & 135 & 300 & $\mathrm{~F}$ \\
\hline PVS & $\mathrm{L}$ & $\mathrm{AqL}$ & Aquasil Ultra+ XLV & & 171017 & October 2020 & 135 & 300 & $\mathrm{~F}, \mathrm{~T}, \mathrm{H}$ \\
\hline PVS & $\mathrm{H}$ & $\mathrm{FtH}$ & Flexitime Heavy Tray & \multirow[b]{2}{*}{ Heraeus Kulzer } & K010157 & August 2020 & 150 & 150 & $\mathrm{~F}$ \\
\hline PVS & $\mathrm{L}$ & $\mathrm{FtC}$ & Flexitime Correct Flow & & R010045 & September 2019 & 150 & 150 & $\mathrm{~F}, \mathrm{~T}, \mathrm{H}$ \\
\hline PVS & $\mathrm{H}$ & $\mathrm{PaH}$ & Panasil tray Soft Heavy & \multirow{2}{*}{ Kettenbach } & 170591075 & September 2019 & 120 & 240 & $\mathrm{~F}$ \\
\hline PVS & $\mathrm{L}$ & $\mathrm{PaL}$ & Panasil Initial contact X-Light & & 170701 & May 2020 & 90 & 150 & $\mathrm{~F}, \mathrm{~T}, \mathrm{H}$ \\
\hline PVS & $\mathrm{H}$ & SyC & Symmetric Comfort & \multirow{2}{*}{ Kaniedenta } & 785984 & April 2021 & 105 & 270 & $\mathrm{~F}$ \\
\hline PVS & $\mathrm{L}$ & FiS & Fitnis SH light & & 61802062 & March 2021 & 90 & 210 & $\mathrm{~F}, \mathrm{~T}, \mathrm{H}$ \\
\hline PVS & $\mathrm{H}$ & $\mathrm{I} 4 \mathrm{H}$ & Imprint 4 Penta Heavy & \multirow{3}{*}{ 3M ESPE } & 3699084 & December 2019 & 120 & 120 & $\mathrm{~F}$ \\
\hline PVS & $\mathrm{L}$ & $\mathrm{I} 4 \mathrm{~L}$ & Imprint 4 Light & & 3944024 & February 2020 & 60 & 120 & $\mathrm{~F}, \mathrm{~T}$ \\
\hline PVS & $\mathrm{L}$ & $\mathrm{I} 4 \mathrm{~L}$ & Imprint 4 Light & & 3714170 & December 2019 & 60 & 120 & $\mathrm{H}$ \\
\hline PE & $\mathrm{H}$ & $\operatorname{ImP}$ & Impregum Penta H Duosoft & \multirow{2}{*}{ 3M ESPE } & 3830139 & July 2020 & 150 & 360 & $\mathrm{~F}$ \\
\hline $\mathrm{PE}$ & $\mathrm{L}$ & $\operatorname{ImL}$ & Impregum Garant L DuoSoft & & $\begin{array}{l}3859100, \\
3737581\end{array}$ & $\begin{array}{c}\text { October 2019, } \\
\text { August } 2019\end{array}$ & 120 & 330 & $\mathrm{~F}, \mathrm{~T}, \mathrm{H}$ \\
\hline VSXE & $\mathrm{L}$ & $\mathrm{IdL}$ & Identium Light & Kettenbach & 170191,180211 & $\begin{array}{l}\text { February 2019, } \\
\text { December } 2019\end{array}$ & 120 & 150 & $\mathrm{~F}, \mathrm{~T}, \mathrm{H}$ \\
\hline
\end{tabular}




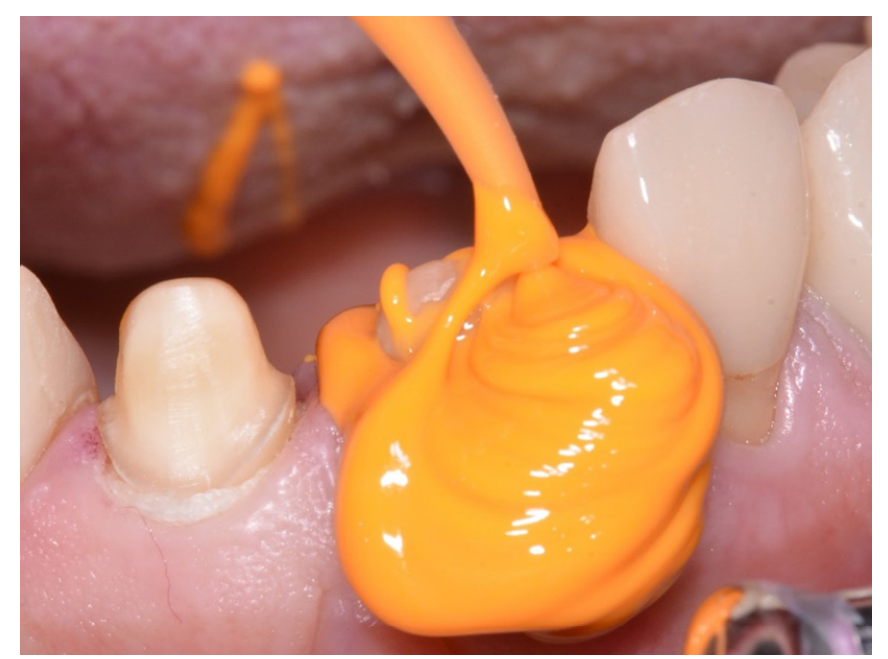

Figure 2. Application of a light-body elastomer to a prepared tooth in the upper jaw. Utilizing the double-mixing technique, the light body material is applied from a cartridge through a mixing canula with a tip directly placed on the hard and soft tissues.

\section{Materials and Methods}

\subsection{Elastomers under Observation}

The clinical setting of a double mixing impression technique was used to investigate heavy-body tray materials and light-body wash materials (Table 1). Since light-body materials are in instant contact with hard and soft tissues (followed by the medium or heavy-body tray material) their behavior towards flowability, hydrophilicity, and tear strength was preferably tested.

\subsection{Testing of the Flowability}

The shark fin testing of the elastomers was facilitated as described by Huettig et al. [9]. The testing device was set up for each elastomer and point in time (Figure 3).

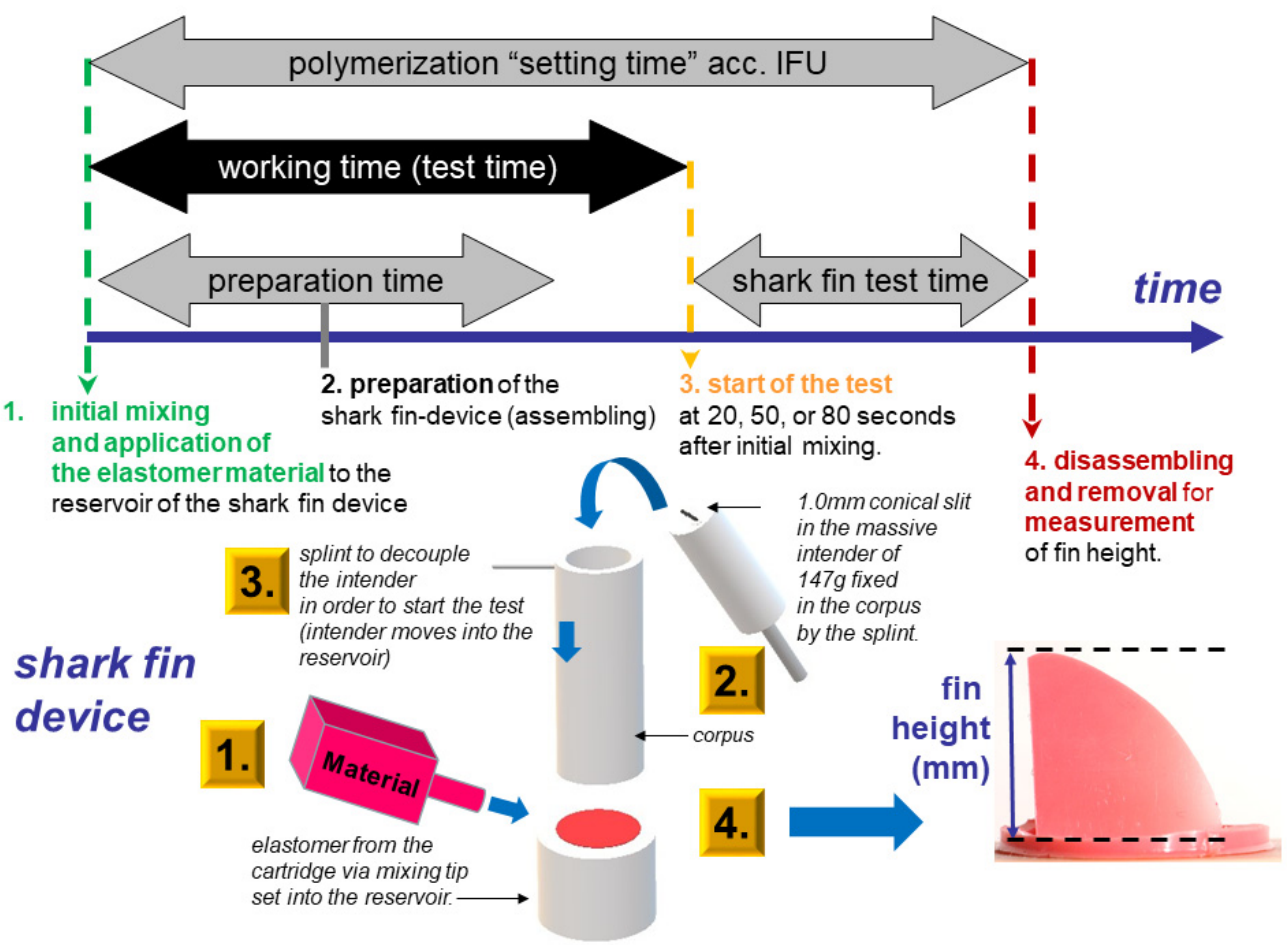

Figure 3. Schematic figure of shark fin testing set up and execution adapted from Huettig et al. [9]. 
Each material was tested alone (single testing) at 20, 50, and $80 \mathrm{~s}$ after their initial mixing. Corresponding heavy and light-body materials were further tested in viscosity combinations (ratio 1:1) at 50 and $80 \mathrm{~s}$ after initial mixing (mixed testing). Fin heights were measured blind with a caliper three times. The mean was used as a final height value (in $\mathrm{mm}$ ) per fin. Each test setting was performed eight times. In total, 21 study groups (14 single, 7 mixed) were established with $\mathrm{N}=8$ specimen per time set ( 3 single, 2 mixed).

\subsection{Testing of the Tear Strength}

The tear strength of light-body materials was performed according to DIN 53504:2017 with the "S2 dumbbell specimen", which was recommended by the technical statute [10]. The specimen had a thickness of $2 \pm 0.2 \mathrm{~mm}$ and a total length of $75 \mathrm{~mm}$ with a bar that was $25 \mathrm{~mm}$ long. The heads were $12.5 \mathrm{~mm}$ wide and the bar was $4 \pm 0.5 \mathrm{~mm}$ wide.

The dumbbell specimens were fabricated via an injection mold that was 3D-designed and additively manufactured using the PolyJet technique (Objet30 OrthoDesk printing VeroGlaze MED620, both Stratasys Corp., Rechovot, Israel) with $28 \mu \mathrm{m}$ layer thickness and glossy surfaces (see Figure 4). Therefore, the printing parameters were set to an isometric uniform scale and supports were selected as "standard" in the printing software (Objet Studio, Stratasys Corp.) The injection mold was provided as an STL file when downloaded as a digital object: 10.5281 /zenodo.4611959.

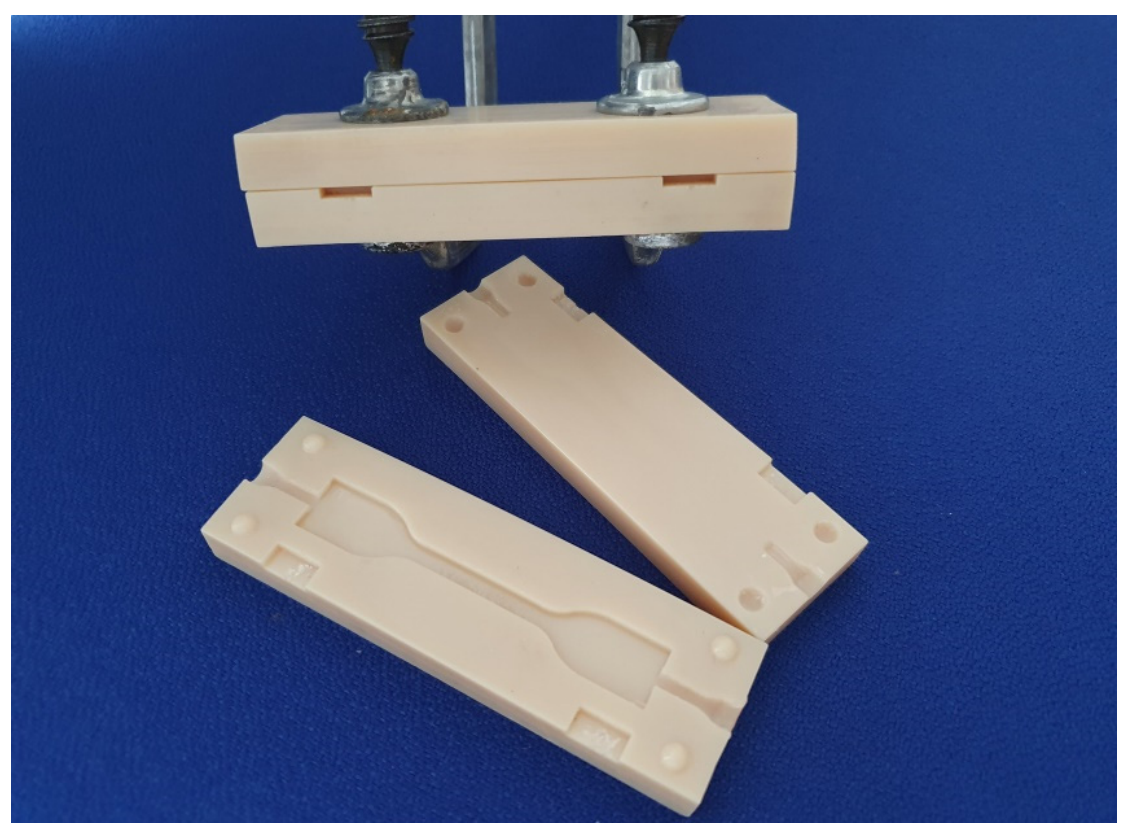

Figure 4. 3D-printed injection mold for the S2 dumbbell specimens (For S2 dumbbell Injection mold please refer to Supplementary Materials). The light-body materials were injected directly after mixing in a closed position (fixed with two screw compressor clamps for tight fit). Moreover, $30 \mathrm{~s}$ prior to the end of setting time, the tool was opened to remove the dumbbell specimen for the tear strength testing procedure. For specifications and object availability, see Section 2.3.

Each study group consisted of $\mathrm{N}=7$ specimens per time set $(\mathrm{T} 0=$ at the end of the setting time (Table 1), T24 = $24 \pm 2 \mathrm{~h}$ later). The testing device (Z020, Zwick-Roell $\mathrm{GmbH}$, Ulm, Germany) was equipped with a force absorber (500 N), a strain meter with (VideoXtens), and a strain measurement. Wedge clamping elements were hydraulic with a distance of $50 \mathrm{~mm}$. Further, they had a $0.1 \mathrm{MPa}$ initial tensile load when the initial testing distance was $20 \mathrm{~mm}$. The speed level of testing was $500 \mathrm{~mm}$ per minute and all tests were performed at $23{ }^{\circ} \mathrm{C}$ in $50 \%$ relative humidity. The tear strength $\sigma_{\max }(\mathrm{MPa})$, percentage elongation at break eR (\%), and tensile strength at 50\% elongation $\sigma 50(\mathrm{MPa})$ were calculated as given in the norm (Figure 5). 


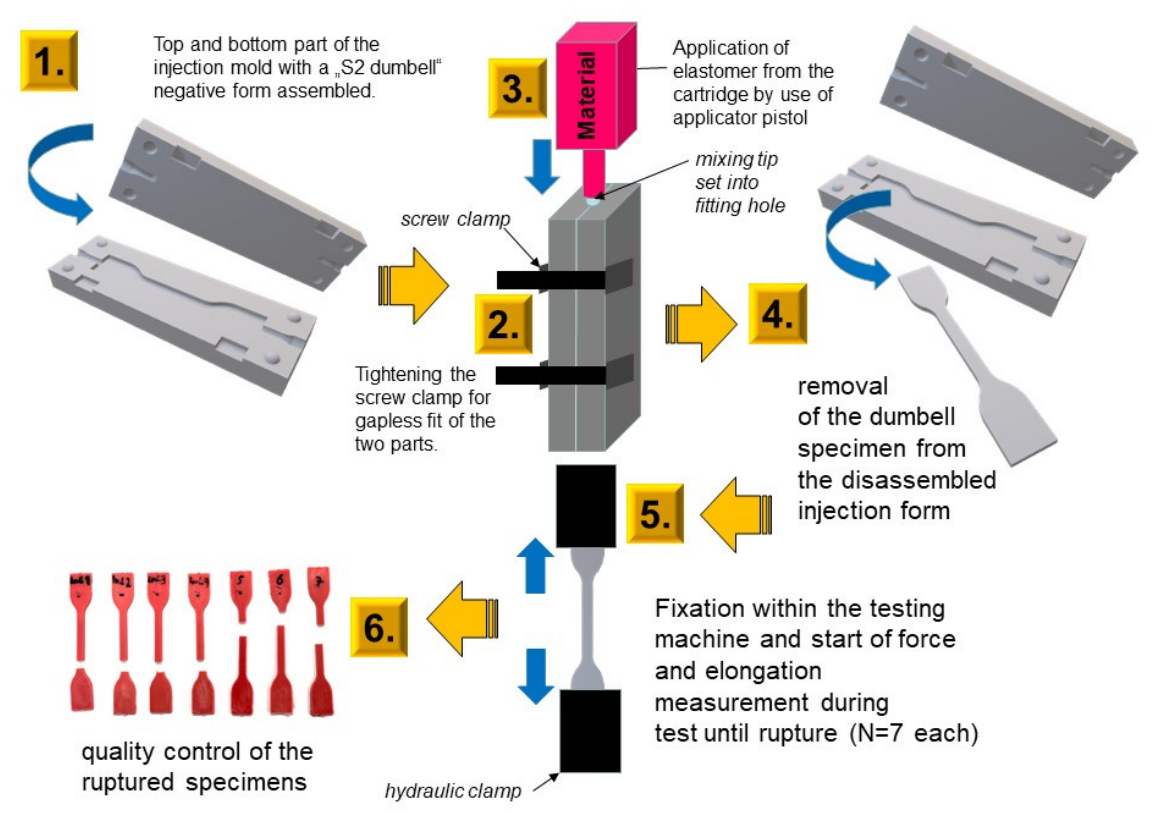

Figure 5. Specimen preparation and testing of the tear strength.

\subsection{Testing of the Hydrophilicity}

Wetting properties of light-body materials were analyzed on unset $(20,50$, and $80 \mathrm{~s}$ after mixing) and set (600 s after mixing) material surfaces via water contact angles. The storage and measuring temperature was $22^{\circ} \mathrm{C}$. Following Figure 6 , the testing was performed in $80 \%$ relative humidity using a climate chamber during contact angle measurements (TPC160, DataPhysics Instruments GmbH, Filderstadt, Germany), which was performed with a drop shape analysis system (OCA200 with SCA software, DataPhysics Instruments $\mathrm{GmbH}$, Filderstadt, Germany). The materials were mixed using intraoral tips according to the manufacturers' instructions. A $50 \mu \mathrm{m}$-thick unset of material films were prepared in a corresponding metal mold, which applied a stainless-steel straightedge. After pre-defined times, $2 \mu \mathrm{L}$ water drops (deionised water) were set onto the surface (Figure 6).

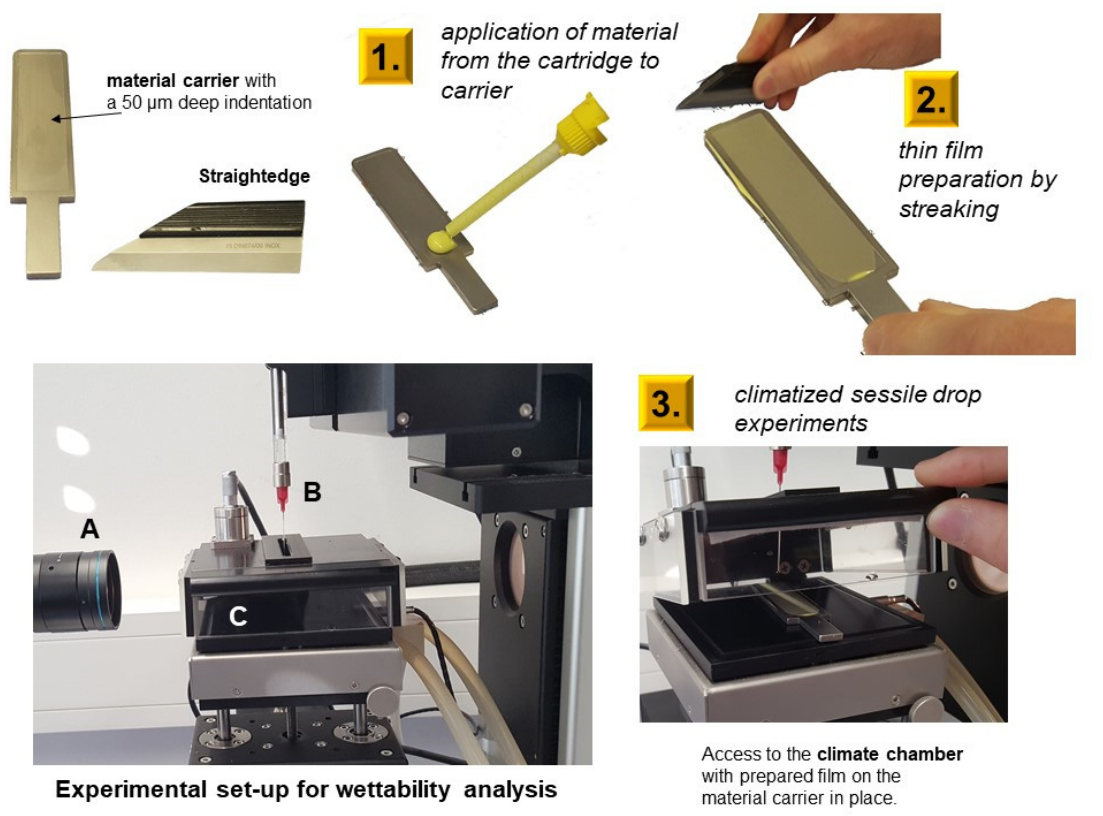

Figure 6. Specimen preparation and testing of hydrophilicity under $80 \%$ relative humidity. The wettability analysis set up contained a high speed video camera (A), microdrop dosage system (B), and climate chamber for specimen presentation (C). 
Drop setting and drop shape development were video-controlled and had a framerate of 25/s for $30 \mathrm{~s}$. Each situation (e.g., material, time after mixing) was repeated fivefold $(\mathrm{N}=5)$. Contact angles were defined as angles in a two-dimensional drop-shape evaluation, wherein three-phase points (solid-liquid-gas) were established between the tangent at the respective drop and the horizontal baseline at the material surface [11]. These were analyzed with drop shapes of $1 \mathrm{~s}, 2 \mathrm{~s}$, and $3 \mathrm{~s}$ after the first water drop surface contact $(\mathrm{t}=0$ when first sharp pic was dropped on the surface). In further calculation, the average of these three measurements was used as a surrogate contact angle to describe hydrophilicity.

\subsection{Statistical Analysis and Sum Score}

The distribution of the obtained variables were initially checked against a normal distribution using Shapiro-Wilk Test $(\alpha=0.05)$. In case of normality, the means were compared using a one-way analysis of variance (ANOVA) and Tukey's post-hoc test. Otherwise, a Wilcoxon signed-rank test was applied for multiple comparisons. All comparisons were run with an $\alpha$ of 0.05 under that the null hypothesis assumption that no difference was present between the groups. A connecting letter report was written to group non-statistically significant distributions from each other. Differences were considered statistically significant when the $\mathrm{p}$ value was less than 0.05 . The following groups were defined for comparison: light-body materials, heavy-body materials, mixed materials, and points in time after mixing or setting.

For a performance cluster, the ranks " $R$ " of each light-body material was summarized as a final score independently from their material group. Therefore, each measurement distribution was not statistically significantly different from other distributions in this measurement group (connecting letter report), which were assigned with a rank, $\mathrm{R}$ (connecting letter $\mathrm{A}=1, \mathrm{~B}=2$, etc.). The ranks gained in each experiment were summarized and divided by the number of experiments. This offered a score with a metric measurement (Equation (1)).

score $=\frac{\left(\begin{array}{c}\frac{R[\text { flowability }](\text { at } 20 \mathrm{~s}+\text { at } 50 \mathrm{~s}+\text { at } 80 \mathrm{~s})}{3} \\ +\frac{R[\text { contact angle }](\text { at } 20 \mathrm{~s}+\text { at } 50 \mathrm{~s}+\text { at } 80 \mathrm{~s}+\text { at } 600 \mathrm{~s})}{4}\end{array}\right)+\left(\begin{array}{c}\frac{R\left[\sigma_{\max } \mathrm{T} 0\right](\text { at } 20 \mathrm{~s}+\text { at } 50 \mathrm{~s}+\text { at } 80 \mathrm{~s})}{3} \\ +\frac{R\left[\sigma_{\max } \mathrm{T} 24\right](\text { at } 20 \mathrm{~s}+\text { at } 50 \mathrm{~s}+\text { at } 80 \mathrm{~s})}{3}\end{array}\right) \div 2}{3}$

Equation (1) demonstrates a formula to calculate the performance score out of the ranks " $R$ " from the single experiments (e.g., flowability at 20 s). A rank is derived from the connecting letter report of the post-hoc statistical testing of distributions.

\section{Results}

\subsection{Flowability}

All materials were suitable to form fins within the test set up at all times after initial mixing. The mean fin heights and ranks $(\mathrm{R})$ were derived from statistically different groups (Tables 2-4).

\subsection{Tear Strength}

The polymerized specimen could be successfully tested in pre-set time frames. The tear strength values at $\mathrm{T} 0$ and $\mathrm{T} 24$ are given in Table 5 . The rupture was located near the radius of the specimens tested at T24 in AqL ( $=4)$; FiS ( $(n=1) ; \operatorname{FtC}(\mathrm{n}=4) ; \operatorname{IL4}(\mathrm{n}=3) ; \operatorname{IdL}(\mathrm{n}=6)$; $\operatorname{ImL}(\mathrm{n}=4)$; and $\mathrm{PaL}(\mathrm{n}=2)$. This is especially true when compared to T0, which was only observed in $\mathrm{FtC}(\mathrm{n}=1)$ and $\operatorname{ImL}(\mathrm{n}=3)$. 
Table 2. Mean and SD of fin heights were derived after testing light-body materials and their ranks (R). Tests had a statistical difference within each time group.

\begin{tabular}{|c|c|c|c|c|c|c|c|c|c|c|c|c|c|c|c|c|c|c|c|c|c|}
\hline \multirow{3}{*}{$\begin{array}{c}\text { Time after } \\
\text { Inital Mixing (s) }\end{array}$} & \multicolumn{21}{|c|}{ Light-Body Materials } \\
\hline & \multicolumn{3}{|c|}{ AqL } & \multicolumn{3}{|c|}{ FiS } & \multicolumn{3}{|c|}{ FtC } & \multicolumn{3}{|c|}{$\mathrm{I} 4 \mathrm{~L}$} & \multicolumn{3}{|c|}{ IdL } & \multicolumn{3}{|c|}{$\operatorname{ImL}$} & \multicolumn{3}{|c|}{$\mathrm{PaL}$} \\
\hline & Mean & SD & $\mathbf{R}$ & Mean & SD & $\mathbf{R}$ & Mean & SD & $\mathbf{R}$ & Mean & SD & $\mathbf{R}$ & Mean & SD & $\mathbf{R}$ & Mean & SD & $\mathbf{R}$ & Mean & SD & $\mathbf{R}$ \\
\hline 20 & 12.12 & 0.62 & 2 & 15.01 & 0.34 & 1 & 9.45 & 0.45 & 4 & 10.82 & 0.31 & 3 & 10.99 & 0.69 & 3 & 15.59 & 0.62 & 1 & 12.81 & 0.53 & 2 \\
\hline 50 & 10.84 & 0.62 & 2 & 10.35 & 0.39 & 2 & 8.31 & 0.46 & 3 & 6.23 & 0.27 & 5 & 10.18 & 0.51 & 2 & 15.92 & 0.81 & 1 & 9.92 & 0.58 & 3 \\
\hline 80 & 9.04 & 0.25 & 2 & 6.94 & 0.74 & 3 & 7.40 & 0.31 & 3 & 3.51 & 0.20 & 5 & 9.46 & 0.28 & 2 & 15.56 & 0.27 & 1 & 7.29 & 0.39 & 3 \\
\hline average & 10.67 & 1.39 & 2 & 10.77 & 3.42 & 2 & 8.39 & 0.95 & 3.3 & 6.85 & 3.09 & 4.3 & 10.21 & 0.81 & 2.3 & 15.69 & 0.60 & 1 & 10.01 & 2.35 & 2.3 \\
\hline
\end{tabular}

Table 3. Mean and SD of fin heights were derived after testing heavy-body materials and their ranks (R). Tests had a statistical difference within each time group.

\begin{tabular}{|c|c|c|c|c|c|c|c|c|c|c|c|c|c|c|c|c|c|c|c|c|c|}
\hline \multirow{3}{*}{$\begin{array}{c}\text { Time after } \\
\text { Inital Mixing (s) }\end{array}$} & \multicolumn{21}{|c|}{ Heavy-Body Materials } \\
\hline & \multicolumn{3}{|c|}{$\mathrm{AqH}$} & \multicolumn{3}{|c|}{$\mathrm{FtH}$} & \multicolumn{3}{|c|}{$\mathrm{I} 4 \mathrm{H}$} & \multicolumn{3}{|c|}{ IdH } & \multicolumn{3}{|c|}{$\operatorname{ImP}$} & \multicolumn{3}{|c|}{$\mathrm{PaH}$} & \multicolumn{3}{|c|}{ SyC } \\
\hline & Mean & SD & $\mathbf{R}$ & Mean & SD & $\mathbf{R}$ & Mean & SD & $\mathbf{R}$ & Mean & SD & $\mathbf{R}$ & Mean & SD & $\mathbf{R}$ & Mean & SD & $\mathbf{R}$ & Mean & SD & $\mathbf{R}$ \\
\hline 50 & 2.35 & 0.05 & 2 & 0.79 & 0.08 & 6 & 1.80 & 0.08 & 3 & 1.72 & 0.07 & 3 & 5.11 & 0.11 & 1 & 1.07 & 0.08 & 5 & 1.57 & 0.11 & 4 \\
\hline 80 & 1.52 & 0.15 & 2 & 0.48 & 0.07 & 6 & 1.20 & 0.08 & 3 & 0.96 & 0.09 & 4 & 4.98 & 0.08 & 1 & 0.67 & 0.03 & 5 & 0.88 & 0.04 & 4 \\
\hline average & 1.94 & 0.44 & 2 & 0.64 & 0.18 & 6 & 1.50 & 0.32 & 3 & 1.34 & 0.40 & 3.5 & 5.05 & 0.11 & 1 & 0.87 & 0.21 & 5 & 1.23 & 0.36 & 4 \\
\hline
\end{tabular}

Table 4. Mean and SD of fin heights were derived after testing the mixed corresponding light and heavy-body materials and their ranks (R) within each time group.

\begin{tabular}{|c|c|c|c|c|c|c|c|c|c|c|c|c|c|c|c|c|c|c|c|c|c|}
\hline \multirow{3}{*}{$\begin{array}{c}\text { Time after } \\
\text { Inital Mixing (s) }\end{array}$} & \multicolumn{21}{|c|}{ Corresponding Materials } \\
\hline & \multicolumn{3}{|c|}{ AqH-AqL } & \multicolumn{3}{|c|}{ FtH-FtC } & \multicolumn{3}{|c|}{ I4H-I4L } & \multicolumn{3}{|c|}{ IdH-IdL } & \multicolumn{3}{|c|}{$\operatorname{ImP-ImL}$} & \multicolumn{3}{|c|}{ PaH-PaL } & \multicolumn{3}{|c|}{ SyC-Fis } \\
\hline & Mean & SD & $\mathbf{R}$ & Mean & SD & $\mathbf{R}$ & Mean & SD & $\mathbf{R}$ & Mean & SD & $\mathbf{R}$ & Mean & SD & $\mathbf{R}$ & Mean & SD & $\mathbf{R}$ & Mean & SD & $\mathbf{R}$ \\
\hline 80 & 8.97 & 0.32 & 2 & 8.12 & 0.59 & 2 & 4.55 & 0.17 & 4 & 8.56 & 0.84 & 2 & 15.66 & 0.63 & 1 & 7.02 & 0.69 & 3 & 6.75 & 0.70 & 3 \\
\hline average & 9.50 & 0.69 & 2.5 & 8.17 & 0.78 & 3 & 6.13 & 1.65 & 4.5 & 8.99 & 1.16 & 2.5 & 16.04 & 0.66 & 1 & 8.49 & 1.80 & 3 & 9.31 & 2.81 & 2.5 \\
\hline
\end{tabular}




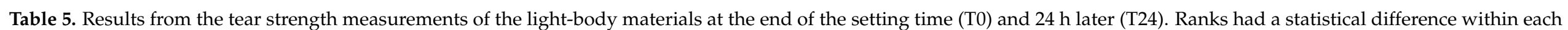
time group.

\begin{tabular}{|c|c|c|c|c|c|c|c|c|c|c|c|c|c|c|c|c|c|c|}
\hline \multirow{3}{*}{ Material } & \multirow{2}{*}{\multicolumn{3}{|c|}{$\begin{array}{c}\text { T0 } \\
\sigma_{50}(\mathrm{MPa})\end{array}$}} & \multirow{2}{*}{\multicolumn{3}{|c|}{$\begin{array}{c}\mathrm{T} 24 \\
\sigma_{50}(\mathrm{MPa})\end{array}$}} & \multirow{2}{*}{\multicolumn{3}{|c|}{$\begin{array}{c}\text { T0 } \\
\text { eR (in \%) }\end{array}$}} & \multirow{2}{*}{\multicolumn{3}{|c|}{$\begin{array}{c}\text { T24 } \\
\text { eR (in \%) }\end{array}$}} & \multirow{2}{*}{\multicolumn{3}{|c|}{$\begin{array}{c}\mathrm{T} 0 \\
\sigma_{\max }(\mathrm{MPa})\end{array}$}} & \multirow{2}{*}{\multicolumn{3}{|c|}{$\begin{array}{c}\mathrm{T} 24 \\
\sigma_{\max }(\mathrm{MPa})\end{array}$}} \\
\hline & & & & & & & & & & & & & & & & & & \\
\hline & Mean & Std Dev & $\mathbf{R}$ & Mean & Std Dev & $\mathbf{R}$ & Mean & Std Dev & $\mathbf{R}$ & Mean & Std Dev & $\mathbf{R}$ & Mean & Std Dev & $\mathbf{R}$ & Mean & Std Dev & $\mathbf{R}$ \\
\hline $\mathrm{AqL}$ & 0.75 & 0.12 & 2 & 1.92 & 0.17 & 1 & 197 & 28.41 & 1 & 108.95 & 8.85 & 3 & 3.72 & 0.39 & 1 & 5.05 & 0.32 & 1 \\
\hline FiS & 0.78 & 0.05 & 2 & 1.20 & 0.08 & 4 & 171 & 39.23 & 1 & 116.99 & 9.85 & 2 & 2.30 & 0.29 & 3 & 2.64 & 0.12 & 3 \\
\hline $\mathrm{FtC}$ & 0.65 & 0.04 & 2 & 0.68 & 0.04 & 5 & 201 & 25.35 & 1 & 183.96 & 28.91 & 1 & 2.07 & 0.23 & 3 & 2.03 & 0.19 & 4 \\
\hline $\mathrm{I} 4 \mathrm{~L}$ & 1.35 & 0.08 & 1 & 1.66 & 0.09 & 2 & 118 & 5.77 & 2 & 102.60 & 8.37 & 3 & 3.00 & 0.18 & 2 & 3.49 & 0.14 & 2 \\
\hline IdL & 1.38 & 0.25 & 1 & 1.44 & 0.05 & 3 & 122 & 25.69 & 2 & 117.13 & 9.39 & 2 & 2.21 & 0.26 & 3 & 2.40 & 0.07 & 3 \\
\hline $\operatorname{ImL}$ & 0.52 & 0.10 & 3 & 1.15 & 0.09 & 4 & 116 & 36.71 & 2 & 85.58 & 19.80 & 3 & 0.75 & 0.14 & 5 & 1.41 & 0.14 & 5 \\
\hline $\mathrm{PaL}$ & 0.81 & 0.17 & 2 & 1.18 & 0.06 & 4 & 179 & 33.03 & 1 & 137.41 & 14.67 & 2 & 1.82 & 0.27 & 4 & 2.21 & 0.09 & 4 \\
\hline
\end{tabular}


Therefore, the load-elongation curves differed, as shown in Figures 7 and 8.

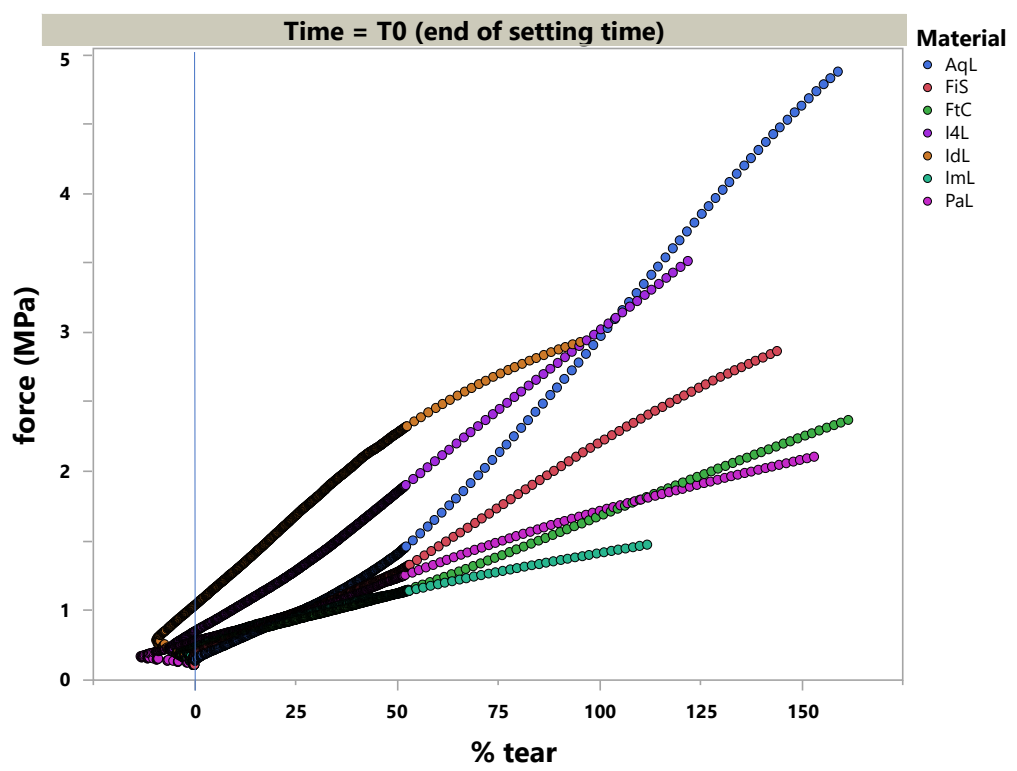

Figure 7. Stress-strain diagram of the light-body materials at the end of setting time (T0.)

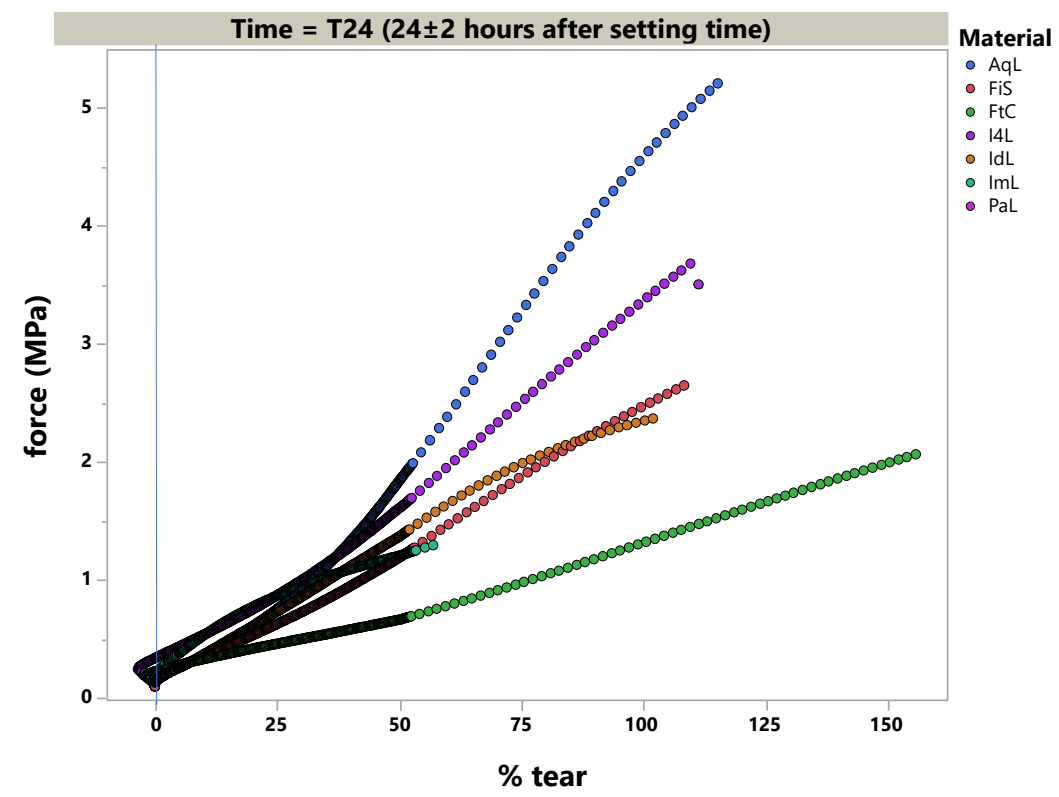

Figure 8. Stress-strain diagram of the light-body materials $24 \mathrm{~h}$ after impression taking (T24).

\subsection{Hydrophilicity}

Table 6 shows the contact angles received from the light-body materials based on the sessile drop technique. The time dependent changes are illustrated in Figure 9. 
Table 6. Results from the contact angle measurements (in ${ }^{\circ}$ ) was used to determine the wetting behavior. Ranks had a statistical difference within each time group.

\begin{tabular}{|c|c|c|c|c|c|c|c|c|c|c|c|c|c|}
\hline \multirow{4}{*}{ Material } & \multicolumn{12}{|c|}{ Time after Initial Mixing (s) } & \multirow[b]{4}{*}{ Mean R } \\
\hline & & 20 & & & 50 & & & 80 & & $600+$ & etting Tim & & \\
\hline & \multicolumn{3}{|c|}{ Contact Angle $\left(^{\circ}\right)$} & \multicolumn{3}{|c|}{ Contact Angle $\left({ }^{\circ}\right)$} & \multicolumn{3}{|c|}{ Contact Angle $\left({ }^{\circ}\right)$} & \multicolumn{3}{|c|}{ Contact Angle ( ${ }^{\circ}$ ) } & \\
\hline & Mean & Std Dev & $\mathbf{R}$ & Mean & Std Dev & $\mathbf{R}$ & Mean & Std Dev & $\mathbf{R}$ & Mean & Std Dev & $\mathbf{R}$ & \\
\hline $\mathrm{AqL}$ & 19.76 & 2.40 & 2 & 18.01 & 1.30 & 2 & 16.82 & 1.22 & 2 & 12.42 & 1.17 & 2 & 2 \\
\hline FiS & 50.97 & 3.08 & 3 & 55.64 & 3.91 & 4 & 64.04 & 3.92 & 4 & 64.33 & 5.05 & 4 & 3.75 \\
\hline $\mathrm{FtC}$ & 70.75 & 4.05 & 4 & 74.11 & 4.36 & 5 & 81.64 & 5.17 & 5 & 92.53 & 5.97 & 5 & 4.75 \\
\hline I4L & 23.62 & 1.86 & 2 & 20.69 & 2.32 & 3 & 16.94 & 2.15 & 2 & 11.10 & 1.53 & 2 & 2.25 \\
\hline IdL & 16.80 & 1.89 & 1 & 14.42 & 1.67 & 1 & 14.05 & 1.62 & 1 & 10.30 & 1.48 & 1 & 1 \\
\hline $\operatorname{ImL}$ & 54.38 & 5.89 & 3 & 52.35 & 5.62 & 4 & 53.32 & 5.96 & 3 & 58.09 & 2.10 & 3 & 3.25 \\
\hline $\mathrm{PaL}$ & 15.47 & 2.10 & 1 & 13.75 & 2.03 & 1 & 13.18 & 2.55 & 1 & 9.74 & 1.39 & 1 & 1 \\
\hline
\end{tabular}

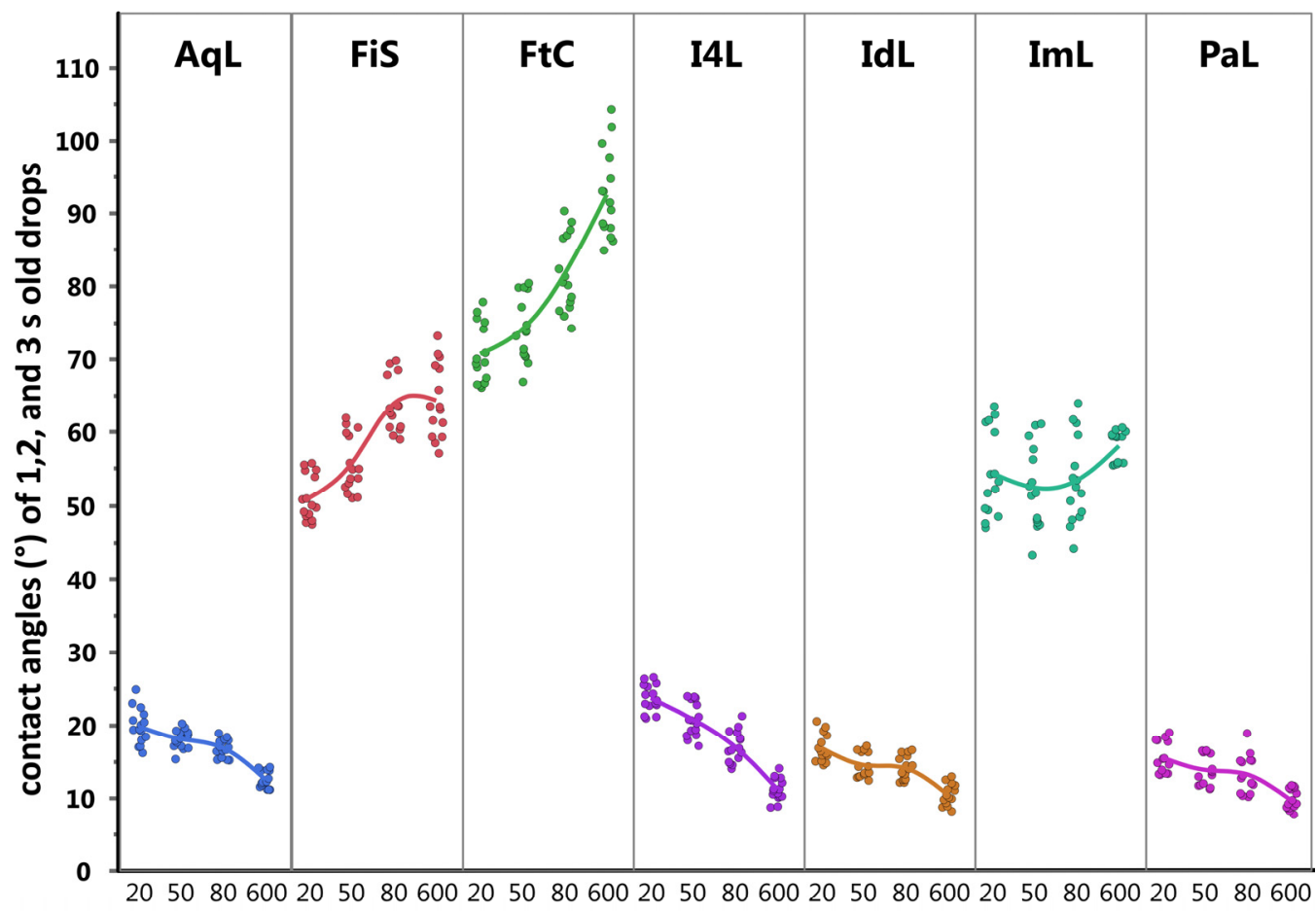

seconds after initial mixing of the elastomer

Figure 9. Wettability behavior over time. Three measured contact angles (y-axis) met at the polymerizing light-body materials after initial mixing (x-axis). Each dot gave one angle measurement at the drop. Scattering of the dots offered insight into spreading behavior of the drop from 1 to $3 \mathrm{~s}$ (15 measurements from 5 specimens per group).

\subsection{Performance Analysis of Light-Body Materials}

The mean ranks derived from the three experiments, as well as the final score, are shown in Table 7. Figure 10 visually interrelates the measured mean values of flowability (fin height), hydrophilicity (contact angle), and tear strength $\left(\sigma_{\max }\right)$, specifically with regard to light-body materials. 
Table 7. Light-body materials rankings from the three experiments, sorted by the final rank (sum score). Green, yellow, and red indicate a score classification of $\leq 2.5, \leq 3.5$, and $>3.5$. * The flowability rank derives from the sum of the mean rank values from light-body materials and the mixed test set up divided by 2 .

\begin{tabular}{ccccc}
\hline Elastomer & Flowability & Hydrophilicity & Tear Strength & $\begin{array}{c}\text { Sum Score } \\
\text { (Final Rank) }\end{array}$ \\
\hline $\mathrm{AqL}$ & 2.17 & 2 & 1.5 & $5.67(1)$ \\
\hline $\mathrm{IdL}$ & 2.77 & 1 & 2.33 & $6.10(2)$ \\
\hline $\mathrm{PaL}$ & 3.43 & 1 & 2.83 & $7.26(3)$ \\
\hline $\mathrm{ImL}$ & 1 & 3.25 & 3.66 & $7.91(4)$ \\
\hline $\mathrm{I} 4 \mathrm{~L}$ & 3.93 & 2.25 & 2 & $8.18(5)$ \\
\hline $\mathrm{FiS}$ & 2.83 & 3.75 & 2.5 & $9.08(6)$ \\
\hline $\mathrm{FtC}$ & 4.1 & 4.75 & 2.67 & $11.52(7)$ \\
\hline
\end{tabular}

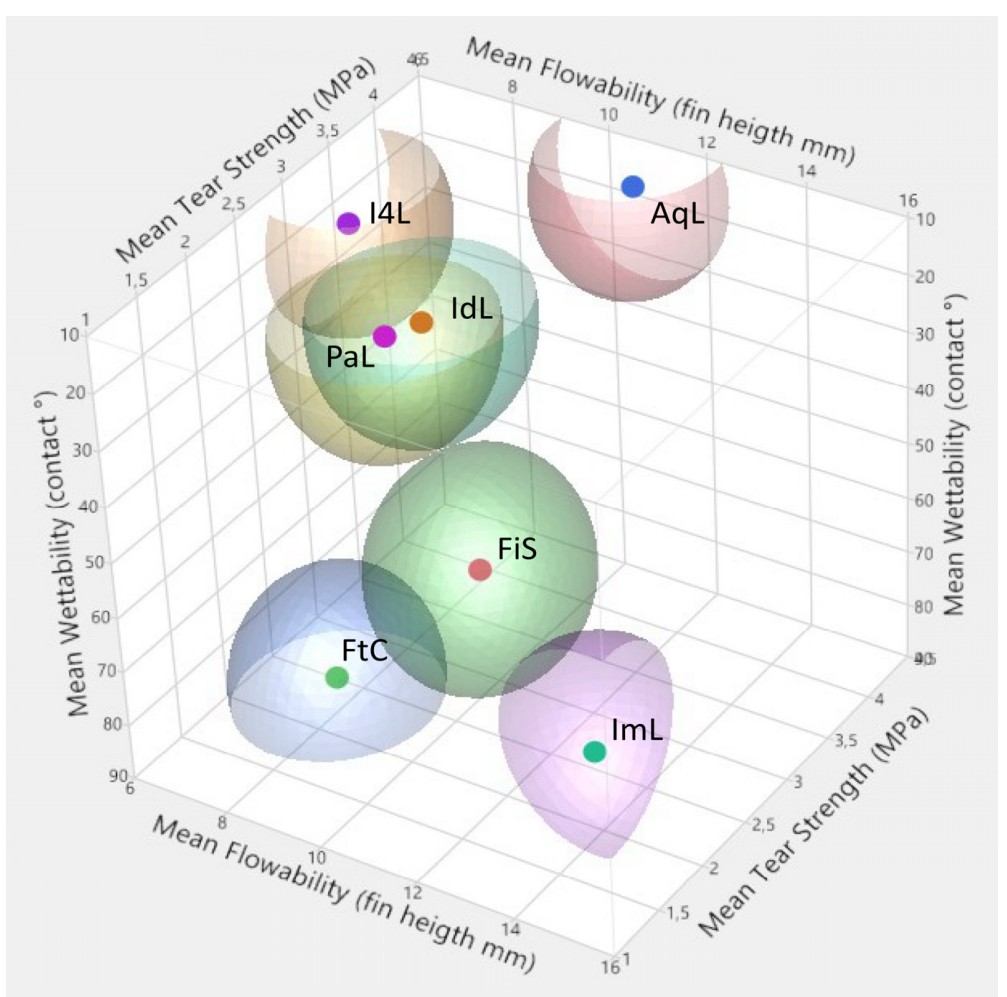

Figure 10. Data illustration that indicates how materials orient around the three tested properties: tear strength, flowability, and wettability.

\section{Discussion}

Because there are many types of impression materials on the market, it is difficult to survey all of the currently used properties [4]. Since 2010, the research terms "impression material" AND "dental" have dropped from about 3 out of 1000 scientific manuscripts to about 2 out of 1000 manuscripts, ranging at 2.37 per 1000 a year (see Appendix A).

As mentioned in the introduction, conventional impressions are still necessary in dental practice, especially vis-à-vis full arch rehabilitations including prosthetic treatment of multiple implants [12]. This process includes detailed reproduction of subgingival areas (not detectable by scanning technologies). Therefore, flowability, wettability, and tear strength are of major academic and practical interest [4].

\subsection{Flowability}

Flowability is strongly connected to an elastomer's viscosity. Light-body materials have high viscosity, but their ability to flow under pressure when clinically applied in a 
tray can differ. Several approaches can be used to test rheological properties such as the application of a rheometer to reveal viscosity (Pa s), elastic modulus ( $\mathrm{kPa}$ ), and tan delta to reveal polymerization over time [7]. Flowability also addresses thixotropic behavior [13].

Shark fin testing offers a device that is easier to use and comprehend the results. However, the test is limited to one time point per test. One may assume that this was why it has been frequently applied to compare flowability under a standardized weight $[7,9,13,14]$. However, the comparison of reported fin heights has been proven to be hindered by the test environment, such as slit width, testing time after initial mixing, room and material temperature, the mode of application (single vs. layered), and dimensions of the applied device itself [15]. Nevertheless, it allows for a comparative view of the tests, which can be conveyed to other tests. As detected by Rupp et al., the clinical time of application is around $80 \mathrm{~s}$ after initial mixing [16].

PE forms have been found to possess the highest fins at $80 \mathrm{~s}$. PVXE and PVS materials possess the second highest fin at $80 \mathrm{~s}$. These findings align with the findings presented in this study $[7,9,14,17]$. This implies that PE may outperform subgingival structures and have an increased risk of cleft formations (as shown in Figure 1) due to its higher tendency to merge while flowing under pressure. Here, PE resulted in constantly high fins (about $15 \mathrm{~mm}$ ) during working times (20,50, and 80s). On the other hand, VSXE showed a slight drop $(-13.9 \%)$ from 20 to $80 \mathrm{~s}$ and PVS dropped between $-21.7 \%$ and $-67.6 \%$ from the initial value. PVS materials also showed a high spread of flowability $80 \mathrm{~s}$ after initial mixing, resulting in a $9 \mathrm{~mm}$ to $3.5 \mathrm{~mm}$ fin height. Consequently, in case of routine shortcomings (e.g., clefts, unrecorded areas) the clinician should reflect the potential influence of flowability to the applied PVS. The PVXE materials may offer a clinical compromise in flowability, as described by Enkling et al. [18].

Finally, one should take into account that a "higher" shark fin "is not necessarily the prerequisite for high dimensional accuracy and good surface detail reproduction of the clinical impressions, respectively" [17].

\subsection{Tear Strength}

High tear strength is a favorable property in elastomers as it enables the clinical avoidance of ruptures and scissures for thin flags that could likely be formed with a retracted sulcus or induced by any interdental space due to the absence of a papilla after the tray is removed from the jaw. In a dental lab setting, when the impression is removed from the cast, a rupture in the impression material may align with a loss of areas that cover the finishing line of abutting teeth. This hinders a second cast fabrication (control cast) of the same detail and validity.

To simulate the clinical situation of demolding, grip separation was set to $500 \mathrm{~mm}$ per minute $(=8.3 \mathrm{~mm} / \mathrm{s})$, which should imitate sulcus acceleration in the moment of removal. Lawson et al. showed that a higher crosshead speed (500 mm vs. $1 \mathrm{~mm}$ per minute) tendentially resulted in higher tear strength values directly after polymerization and $24 \mathrm{~h}$ later. Moreover, their test setting revealed two to three fold higher values (ranging from about 2-8 MPa) for PE, PVXE, and PVS due to different specimens [19]. Testing according to the statute for elastomers revealed small standard deviations (comparable to other studies), but it also failed specimens due to their impermissible rupture mode. This could be attributed to trapped air or merging failures within the injection mold. This observation may offer further research opportunities for the flowing and merging behaviors of elastomers. Pandey et al. used $50 \mathrm{~mm} / \mathrm{min}$ and found comparable behavior in the order of tear strength values, i.e., PE $<$ VSXE < PVS. However, they did not report the testing time [20]. This shows that, over the past four decades, PVS tear strength improved over time compared to PE [21], and outperformed by one specific material in this study (AqL).

In summary, the tear strength of PVS and VSXE materials was found to be superior to PE materials. 


\subsection{Wettability}

Liquids contacting solid materials and how they spread after contact can be characterized and quantified by contact angles. Considering the thermodynamic nature of energetic surface calculations and the so-called Young contact angle, a liquid's drop shape on solid surfaces can form as a result of different interfacial energies [11]. Besides thermodynamic rules, this is useful in non-ideal inhomogeneous systems to measure apparent contact angles even on non-solid, unset material films. This is because they can be used as an indicator of wettability or hydrophilicity (if water is the liquid used). Several studies have shown the appropriateness of experimental approaches that used sessile drop measurements on set and unset polymerizing elastomeric materials $[16,22,23]$. The concept of using so-called initial but unequilibrated contact angles soon after contact has been proven useful for characterizing the hydrophilic state of an impression material when it first contacts an oral surfaces. In the current study, a climate chamber was used to simulate oral relative humidity, which has been shown in an earlier study to possibly influence wetting properties of impression materials [24]. In this study, two PVS materials (FiS and FtC) showed a loss of hydrophilic properties during working time and polymerization, whereas all other materials showed constant or even decreasing contact angles. Three PVS materials and the VSXE material outperformed the polyether $(\operatorname{ImL})$ with significantly lower contact angles, respectively. In this group of four materials, the contact angles ranged between $16.9^{\circ}$ (I4L) and $13.2^{\circ}(\mathrm{PaL}) 80 \mathrm{~s}$ after initial mixing. This, therefore, characterized the very hydrophilic materials. At this time point, a much lower hydrophilicity was ascribed to $\operatorname{ImL}$, FiS, and especially to $\mathrm{FtC}$, which had the highest mean contact angle of $81.6^{\circ}$. Similarly to the unset situation, set impression materials can be subdivided into a very hydrophilic group, a moderate hydrophilic group, and a low hydrophilic group. The latter group is formed by $\mathrm{FtC}$, which has a $92.5^{\circ}$ mean contact angle in the set state and is the only material that exceeds the 90-degree boundary that separates hydrophilic from hydrophobic surface properties. Moreover, the moderate yet constant hydrophilic characteristic is a typical wetting behavior of polyethers due to their hydrophilic chemical structure. Earlier studies often showed a reduction of their initial hydrophilicity in PVS. This was because the material was in a hydrophobic state at the end of the working time, indicating that the active surface was more limited due to its limited molecular mobility in an almost polymerized state [16]. The current study shows that the current generation of PVS materials remains hydrophilic, even though some materials have become less hydrophilic.

In summary, the general "hydrophobic character" of PVS was found to only be valid for a few materials [4].

\subsection{Limitations}

This study investigated three major properties of impression materials. Our findings are of clinical relevance and their impact is visually detectable by clinicians after taking an impression. However, this study excluded the following considerations: detailed reproduction under dry and wet conditions; dimensional stability (i.e., shrinkage and swelling) in dry and wet conditions, as well as thermal expansion behavior; compression and reset; stickiness and interaction with astringents or patient-relevant variables, such as comfort or taste. Furthermore, some clinical circumstances that may interact with the evaluated properties was lacking due to standardization. More specifically, we were unable to verify the impact of temperature on flowability and wettability, or the effect of disinfection and disinfectants after polymerization on wettability and tear strength [25].

\section{Conclusions}

Current elastomers show favorable yet diverging properties (i.e., flowability, wettability, and tear strength). Current PVS and VSXE provide wetting behavior that is superior to PE. Here, tear strength $\sigma_{\max }$ ranged between 2 and $3 \mathrm{MPa}$ for PVS and VSXE after setting times. It also underwent less than $1 \mathrm{MPa}$ for PE. This could have caused a higher risk of ruptures in PE when recording subgingival areas because it had a higher flowability 
than VSXE and PVS. The clinical PVS was relevant to these properties and thus should be critically reflected by observations in dental practice, as well as investigated in academia. Based on these results, we hypothesize that impression materials that show an overall "good" score in all properties might be clinically superior to materials with a "very good" score for only one characteristic.

In summary, our results indicated that VSXE and novel PVS materials were capable of compensating for the shortcomings of $\mathrm{PE}$, specifically towards tear strength and hydrophilicity, but not flowability.

Supplementary Materials: Injection mold of S2 dumbell for download as digital object in STL is available via: https:// doi.org/10.5281/zenodo.4611959.

Author Contributions: Conceptualization and methodology, F.H. and F.R.; formal analysis, F.H.; investigation, A.K. (Andrea Klink), A.K. (Alexander Kohler), and M.M.; resources, F.R.; methodology 3D-designs, M.M.; data curation, F.H., A.K. (Andrea Klink), and M.M.; writing—original draft preparation, F.H.; writing—review and editing, F.R., F.H., A.K. (Andrea Klink), M.M., and A.K. (Alexander Kohler); visualization, F.H.; supervision, F.R.; project administration, A.K. (Andrea Klink); funding acquisition, F.H. and F.R. All authors have read and agreed to the published version of the manuscript.

Funding: The study was financially supported by Dentsply Sirona (Bensheim, Germany). They served as a sponsor and manufacturer of Aquasil ultra+, which was part of the investigation.

Institutional Review Board Statement: This in-vitro study endorsed no patients and therewith was not reviewed by the Ethics Commission.

Informed Consent Statement: Not applicable.

Data Availability Statement: Measurement data are available without restrictions upon request.

Acknowledgments: The authors would like to thank Sebastian Wagner (Natural and Medical Science Institute, Reutlingen, Germany) for his support with tear strength testing. Furthermore, we acknowledge support by Open Access Publishing Fund of University of Tübingen.

Conflicts of Interest: The authors declare no conflict of interest since funding was arranged with the university account and none of the authors received personal compensations. None of the authors works or consult with the manufacturers whose products were under evaluation. The study was run in a scientific setting and therefore the methods, results, and manuscript have not been previewed nor edited by the sponsor or a third party with a potential conflict of interest.

\section{Appendix A}

Table A1. Annual results when searching "impression material" And "dental" in Pubmed Library.

\begin{tabular}{cccc}
\hline Year & $\begin{array}{c}\text { "Dental" } \\
\text { (N Results) }\end{array}$ & $\begin{array}{c}\text { "Impression Material” } \\
\text { AND “Dental” } \\
\text { (N Results) }\end{array}$ & $\begin{array}{c}\text { Share Out of } \\
\text { 1000 Results (\%) }\end{array}$ \\
\hline 2010 & 16,001 & 53 & 3.31 \\
\hline 2011 & 18,248 & 44 & 2.41 \\
\hline 2012 & 19,949 & 60 & 3.01 \\
\hline 2013 & 21,386 & 62 & 2.90 \\
\hline 2014 & 23,378 & 62 & 2.65 \\
\hline 2015 & 24,964 & 54 & 2.16 \\
\hline 2016 & 25,290 & 47 & 1.86 \\
\hline 2017 & 25,556 & 45 & 1.76 \\
\hline 2018 & 26,075 & 55 & 2.11 \\
\hline 2019 & 26,871 & 61 & 2.27 \\
\hline 2020 & 30,737 & 49 & 1.59 \\
\hline
\end{tabular}




\section{References}

1. Chochlidakis, K.M.; Papaspyridakos, P.; Geminiani, A.; Chen, C.J.; Feng, I.J.; Ercoli, C. Digital versus conventional impressions for fixed prosthodontics: A systematic review and meta-analysis. J. Prosthet. Dent. 2016, 116, 184-190.e112. [CrossRef] [PubMed]

2. Flugge, T.; van der Meer, W.J.; Gonzalez, B.G.; Vach, K.; Wismeijer, D.; Wang, P. The accuracy of different dental impression techniques for implant-supported dental prostheses: A systematic review and meta-analysis. Clin. Oral Implants Res. 2018, 29 (Suppl. 16), 374-392. [CrossRef] [PubMed]

3. Stober, T.; Johnson, G.H.; Schmitter, M. Accuracy of the newly formulated vinyl siloxanether elastomeric impression material. J. Prosthet. Dent. 2010, 103, 228-239. [CrossRef]

4. Hamalian, T.A.; Nasr, E.; Chidiac, J.J. Impression materials in fixed prosthodontics: Influence of choice on clinical procedure. J. Prosthodont. 2011, 20, 153-160. [CrossRef] [PubMed]

5. Papadiochos, I.; Papadiochou, S.; Emmanouil, I. The Historical Evolution of Dental Impression Materials. J. Hist. Dent. 2017, 65, 79-89.

6. Donovan, T.E.; Chee, W.W.L. A review of contemporary impression materials and techniques. Dent. Clin. N. Am. 2004, 48, 445-470. [CrossRef]

7. German, M.J.; Carrick, T.E.; McCabe, J.F. Surface detail reproduction of elastomeric impression materials related to rheological properties. Dent. Mater. 2008, 24, 951-956. [CrossRef] [PubMed]

8. Rubel, B.S. Impression materials: A comparative review of impression materials most commonly used in restorative dentistry. Dent. Clin. N. Am. 2007, 51, 629-642. [CrossRef] [PubMed]

9. Huettig, F.; Chekhani, U.; Klink, A.; Said, F.; Rupp, F. A modified shark-fin test simulating the single-step/double-mix technique: A comparison of three groups of elastomers. Dent. Mater. J. 2018, 37, 414-421. [CrossRef] [PubMed]

10. DIN. DIN 53504: Testing of Rubber-Determination of Tensile Strength at Break, Tensile Stress at Yield, Elongation at Break and Stress Values in a Tensile Test; Deutsches Insitut für Normung: Berlin, Germany, 2017; Volume DIN 53504, p. 20.

11. Rupp, F.; Gittens, R.A.; Scheideler, L.; Marmur, A.; Boyan, B.D.; Schwartz, Z.; Geis-Gerstorfer, J. A review on the wettability of dental implant surfaces I: Theoretical and experimental aspects. Acta Biomater. 2014, 10, 2894-2906. [CrossRef] [PubMed]

12. Schmidt, A.; Klussmann, L.; Wöstmann, B.; Schlenz, M.A. Accuracy of Digital and Conventional Full-Arch Impressions in Patients: An Update. J. Clin. Med. 2020, 9, 688. [CrossRef] [PubMed]

13. Tolidis, K.; Tortopidis, D.; Gerasimou, P.; Theocharidou, A.; Boutsiouki, C. Comparison of elastomeric impression materials' thixotropic behavior. Eur. J. Prosthodont. Restor. Dent. 2013, 21, 75-78. [PubMed]

14. Lawson, N.C.; Cakir, D.; Ramp, L.; Burgess, J.O. Flow profile of regular and fast-setting elastomeric impression materials using a shark fin testing device. J. Esthet. Restor. Dent. 2011, 23, 171-176. [CrossRef] [PubMed]

15. Hamid, H. Commentary. Flow profile of regular and fast-setting elastomeric impression materials using a shark fin testing device. J. Esthet. Restor. Dent. 2011, 23, 177-178. [CrossRef] [PubMed]

16. Rupp, F.; Saker, O.; Axmann, D.; Geis-Gerstorfer, J.; Engel, E. Application times for the single-step/double-mix technique for impression materials in clinical practice. Int. J. Prosthodont. 2011, 24, 562-565. [PubMed]

17. Balkenhol, M.; Wöstmann, B.; Kanehira, M.; Finger, W.J. Shark fin test and impression quality: A correlation analysis. J. Dent. 2007, 35, 409-415. [CrossRef] [PubMed]

18. Enkling, N.; Bayer, S.; Jöhren, P.; Mericske-Stern, R. Vinylsiloxanether: A new impression material. Clinical study of implant impressions with vinylsiloxanether versus polyether materials. Clin. Implant. Dent. Relat. Res. 2012, 14, 144-151. [CrossRef]

19. Lawson, N.C.; Burgess, J.O.; Litaker, M. Tear strength of five elastomeric impression materials at two setting times and two tearing rates. J. Esthet. Restor. Dent. 2008, 20, 186-193. [CrossRef] [PubMed]

20. Pandey, P.; Mantri, S.; Bhasin, A.; Deogade, S.C. Mechanical Properties of a New Vinyl Polyether Silicone in Comparison to Vinyl Polysiloxane and Polyether Elastomeric Impression Materials. Contemp. Clin. Dent. 2019, 10, 203-207. [CrossRef] [PubMed]

21. Sneed, W.D.; Miller, R.; Olson, J. Tear strength of ten elastomeric impression materials. J. Prosthet. Dent. 1983, 49, 511-513. [CrossRef]

22. Rupp, F.; Axmann, D.; Jacobi, A.; Groten, M.; Geis-Gerstorfer, J. Hydrophilicity of elastomeric non-aqueous impression materials during setting. Dent. Mater. 2005, 21, 94-102. [CrossRef] [PubMed]

23. Rupp, F.; Geis-Gerstorfer, J. Hydrophilicity of unset and set elastomeric impression materials. Int. J. Prosthodont. 2010, $23,552-554$. [PubMed]

24. Rupp, F.; Axmann, D.; Geis-Gerstorfer, J. Effect of relative humidity on the hydrophilicity of unset elastomeric impression materials. Int. J. Prosthodont. 2008, 21, 69-71. [PubMed]

25. Nassar, U.; Chow, A.K. Surface Detail Reproduction and Effect of Disinfectant and Long-Term Storage on the Dimensional Stability of a Novel Vinyl Polyether Silicone Impression Material. J. Prosthodont. 2015, 24, 494-498. [CrossRef] [PubMed] 